\title{
PENGARUH MEDIA PUZZLE TERHADAP HASIL BELAJAR PADA PEMBELAJARAN IPS DI SEKOLAH DASAR
}

\author{
Laelia Nurpratiwiningsih*1, Atikah Mumpuni ${ }^{2}$ \\ ${ }^{1,2}$ Prodi Pendidikan Guru Sekolah Dasar, Fakultas Keguruan dan Ilmu Pendidikan \\ Universitas Muhadi Setiabudi Brebes, Indonesia \\ e-mail: laelia.np89@gmail.com
}

\begin{abstract}
ABSTRAK
Peran guru dalam pemilihan media pembelajaran sangat penting, terutama terhadap hasil belajar peserta didik. Tujuan penelitian ini yaitu untuk mengetahui pengaruh media puzzle terhadap hasil belajar IPS di Sekolah Dasar. Jenis penelitian yang digunakan penelitian eksperimen. Populasi dalam penelitian ini adalah peserta didik kelas IV di SD Negeri Siwungkuk Pengambilan sampel dilakukan dengan cara random sampling. Teknik pengumpulan data dengan cara tes, observasi dan dokumentasi. Uji analisis dapat dilakukan dengan uji t-test dengan mengukur uji normalitas dan homogenitas terlebih dahulu. Berdasarkan hasil analisis menunjukkan bahwa tabel independent sample test pada hasil belajar peserta didik dapat diketahui bahwa nilai sig $=0,000<0,05$. Hal ini membuktikan bahwa media pembelajaran puzzle dapat berpengaruh terhadap hasil belajar kognitif pada pembelajaran IPS di Sekolah Dasar. Jadi, dapat disimpulkan bahwa media puzzle ini dapat menjadi salah satu solusi dalam pembelajaran IPS di SD khususnya pada materi peta.
\end{abstract}

Kata Kunci: Puzzle, Hasil Belajar, IPS

\section{Abstract}

The role of teachers in selecting learning media is very important, especially its effect on students' achievement. This research aims to find out the effect of puzzle media towards the students' learning achievement on Social Science (IPS) subject. The type of this research is experimental study. Population is students of grade IV in SD Negeri Siwungkuk. Collecting sample is through random sampling. Data collecting techniques use test, observation and documentation. Analysis test uses t-test through calculating normality and homogeneity test. Based on analysis result, table of independent sample test in students' achievement shows that the score of sign $=0,000<0,05$. It proves that learning media of puzzle gives an effect on the result of cognitive learning on Social Science (IPS) subject in Elementary School. It can be concluded that puzzle media can be a solution in teaching learning of Social Science (IPS) subject especially in map material.

Keyword: Puzzle, Achievement, Social Science

\section{PENDAHULUAN}

Pendidikan merupakan proses pembelajaran bagi peserta didik untuk dapat mengerti, paham dan kritis berpikir. Proses pendidikan dapat terlaksana dengan adanya komponen pendidikan. Komponen pendidikan terdiri dari tujuan pendidikan, peserta didik, pendidik, metode pendidikan, materi pendidikan, lingkungan pendidikan, alat dan fasilitas pendidikan. Selain itu, Media pembelajaran juga merupakan salah satu hal yang penting dalam proses pendidikan. Media pembelajaran adalah segala sesuatu yang dapat menyalurkan pesan, dapat merangsang fikiran, perasaan, dan kemauan peserta 
Jurnal KONTEKSTUAL, Volume 1, No. 1, Agustus 2019, pp. 1-6

didik sehingga dapat mendorong terciptanya proses belajar pada diri peserta didik.

Media pembelajaran dapat mempermudah guru dalam proses belajar mengajar. Peserta didik akan lebih mudah memahami materi, ketika penyampaian guru menggunakan media pembelajaran. Bahan ajar juga merupakan salah satu bagian dari media pembelajaran. Bahan ajar efektif diterapkan dalam perkuliahan semantik[1] dimana hal ini membuktikan bahwa sebagai seorang pendidik harus terampil dalam menyampaikan materi. Selain itu, Hal ini dapat berdampak pada hasil belajar peserta didik. Sedangkan hasil belajar adalah perubahan tingkah laku yang mencakup bidang kognitif, afektif dan psikomotorik setelah peserta didik menerima pengalaman belajar[2]. Hasil belajar kognitif ini terfokus pada kegiatan dan aktifitas peserta didik dimana guru melihat ketrampilan peserta didik dalam kegiatan belajar mengajar.

Kenyataan di lapangan menunjukkan bahwa guru di SD Siwungkuk Kecamatan Wanasari Kabupaten Brebes, belum maksimal dalam menggunakan media pembelajaran. Pembelajaran IPS yang berlangsung masih terpusat pada guru. Guru kurang menggali potensi yang dimiliki peserta didik ketika menyampaikan materi pelajaran. Hal ini mengakibatkan peserta didik kurang terlibat dalam proses pembelajaran IPS dan pendekatan pembelajaran yang digunakan dalam proses pembelajaran selama ini kurang menarik. Selain itu, sikap sosial peserta didik kelas IV SD masih rendah. Hal ini terlihat pada peserta didik yang kurang aktif dalam kegiatan pembelajaran. Pemahaman peserta didik terkait pembelajaran IPS masih kurang.
Pembelajaran IPS kelas IV pada tema lingkungan tempat tinggal membutuhkan media pembelajaran yang interaktif. Puzzle diharapkan dapat menjadi salah satu media pembelajaran bagi peserta didik dalam memahami materi peta. Puzzle termasuk dalam permainan yang mengandung kegiatan asosiatif menghubungkan atau merangkaikan. Tugas pemain yaitu menyusun kembali atau menata ulang suatu sistem acak. Penelitian bermaksud untuk mengetahui "Pengaruh Media Puzzle terhadap Hasil Belajar pada Pembelajaran IPS di Sekolah Dasar".

\section{KAJIAN TEORI}

A. Media Puzzle

Puzzle adalah permainan menyusun suatu gambar atau benda yang telah dipecah dalam beberapa bagian. Media puzzle bermanfaat untuk kreatifitas siswa, keaktifan siswa, dan menghidupkan rasa ingin tahu siswa, sehingga pengetahuan siswa akan bertambah[3]. Media puzzle merupakan media pembelajaran yang sifatnya memberikan rasa nyaman berpikir berfikir melalui permainan sehingga lebih menarik dan tertarik.

Media puzzle menggunakan gambar untuk mengkomunikasikan dengan peserta didik. Kelebihan dari gambar antara lain sebagai berikut: 1) gambar sifatnya konkrit lebih realis menunjukkan pada pokok masalahmasalah bila dibandingkan dengan verbal semata, 2) gambar dapat mengatasi ruang dan waktu, artinya tidak semua benda, objek peritiwa dapat dibawa ke kelas dan pembelajar dapat membawa objek tersebut, 3) gambar dapat mengatasi keterbatasan panca indera, 4) memperjelas suatu sajian masalah dalam bidang apa saja dan untuk tingkat usia berapa saja, dan 5) media ini lebih murah harganya, mudah 
didapatkan dan digunakan tanpa memerlukan alat khusus[4].

Selain itu, gambar juga memiliki kelemahan dalam penggunaaannya, kelemahan tersebut antara lain sebagai berikut: 1) lebih menekankan persepsi indra mata, 2) benda terlalu kompleks, kurang efektif untuk pembelajaran, 3) ukuran sangat terbatas untuk kelompok terbatas, 4) harus autentik artinya bahwa gambar tersebut haruslah secara jujur melukiskan situasi adanya, 5) sederhana, komposisi hendaklah cukup jelas menunjukkan point-point pokok dalam gambar, 6) ukurannya relatif, tidak terlalu besar atau terlalu kecil, tetapi sesuai dengan kebutuhan, 7) gambar menunjukkan suatu aktivitas, kegiatan atau perbuatan tertentu, dan 8)gambar yang bagus belum tentu mencapai tujuan pembelajaran.

\section{B. Hasil Belajar}

Hasil belajar adalah perubahan tingkah laku peserta didik akibat proses kegiatan belajar mengajar, yang berupa perubahan dalam aspek kognitif, afektif dan psikomotorik. Hasil belajar kognitif merupakan aspek yang berkaitan dengan intelektual[5]. Ada enam tingkatan dalam aspek kognitif, yaitu pengetahuan, pemahaman, penerapan, analisis, sintesis dan evaluasi.

Aspek dalam penelitian ini, lebih difokuskan pada pengetahuan, pemahaman, penerapan dan analisis. Tipe hasil belajar pengetahuan adalah tingkatan yang paling rendah tapi tipe belajar ini penting sebagai prasarat untuk menguasai dan mempelajari tipe hasil belajar lain yang lebih tinggi. Tipe hasil belajar pemahaman adalah kemampuan untuk mengungkapkan makna atau arti dari suatu konsep. Tipe hasil belajar penerapan adalah kesanggupan menerapkan dan mengabstraksi suatu konsep, ide, rumus, hukum dalam situasi yang baru. Dan
Tipe hasil belajar analisis adalah kesanggupan memecahkan, mengurai suatu integritas menjadi unsur-unsur yang mempunyai arti.

Tujuan pembelajaran kognitif adalah tujuan-tujuan yang lebih banyak berkenaan dengan perilaku dalam aspek berpikir[6]. Hasil belajar kognitif merupakan suatu pencapaian dalam proses kegiatan belajar mengajar di kelas.

Faktor-faktor yang dapat mempengaruhi belajar dapat dikelompokkan menjadi 2, yaitu faktor ekstern dan faktor intern. Faktor ektern terdiri dari jasmani, psikologis dan kelelahan. Sedangkan faktor intern, terdiri dari keluarga, sekolah dan masyarakat[7]

\section{Pembelajaran IPS \\ IPS merupakan muatan pembelajaran yang terdapat dalam kurikulum sekolah, terutama} mempelajari hubungan-hubungan antar manusia dalam budaya dan daerahnya. Sedangkan tujuan dari pendidikan IPS diarahkan pada pembentukan sikap dan kepribadian profesional serta peningkatan penguasaan pengetahuan dan ketrampilan fungsional peserta didik[8]. Pendidikan IPS harus mampu mengembangkan pemahaman peserta didik terhadap pengalaman hidup masyarakat, pemahaman kritis terhadap ilmu-ilmu sosial, pemahaman terhadap manusia dalam konteks persatuan dalam perbedaan, dan analisis kritis terhadap keadaan kehidupan manusia.

\section{METODE PENELITIAN}

Penelitian ini menggunakan
metode eksperimen dan desain
penelitian yang digunakan adalah True
Experimental Design. Ciri utama dari
True Experimental Design adalah
bahwa sampel yang digunakan untuk
eksperimen maupun kelompok kontrol


Jurnal KONTEKSTUAL, Volume 1, No. 1, Agustus 2019, pp. 1-6

diambil secara random dari populasi tertentu[9]. Dalam penelitian ini kelas eksperimen I menggunakan perlakuan yaitu media puzzle, sedangkan kelas eksperimen II tanpa menggunakan perlakuan, seperti: metode ceramah. Bentuk desain penelitian True Experimental menggunakan PosttestOnly Control Design.

Populasi dalam penelitian ini dilakukan di kelas IV SD Negeri Siwungkuk. Pengambilan sampel menggunakan random sampling. Teknik pengumpulan data menggunakan tes, observasi dan dokumentasi. Uji hipotesis dilakukan dengan $t$-test.

\section{HASIL DAN PEMBAHASAN}

Pengujian hasil penelitian dilakukan dengan uji normalitas dan uji homogenitas data terlebih dahulu.

1. Uji Normalitas

Pengujian normalitas bertujuan untuk mengetahui apakah data tersebut berdistribusi normal atau tidak. Berdasarkan data tabel 1. dapat diketahui bahwa nilai signifikasi uji normalitas antara kelas eksperimen dengan kelas kontrol di SD Negeri Siwungkuk adalah 0,230>0,05. Hal ini berarti varian dari dua atau lebih kelompok populasi data berdistribusi normal.

\section{Tabel 1. Tabel Uji Normalitas}

\begin{tabular}{ccccccc}
\hline & \multicolumn{3}{c}{$\begin{array}{c}\text { Kolmogorov- } \\
\text { Smirnov }\end{array}$} & \multicolumn{3}{c}{ Shapiro-Wilk } \\
\cline { 2 - 7 } & $\begin{array}{c}\text { Statis } \\
\text { tic }\end{array}$ & Df & Sig. & $\begin{array}{c}\text { Statis df } \\
\text { tic }\end{array}$ & Sig. \\
\hline $\begin{array}{c}\text { Hasil } \\
\text { Belajar }\end{array}$ & .082 & 52 & .200 & .971 & 52 & .230 \\
\hline
\end{tabular}

a. Lilliefors Significance Correction

This is a lower bound of the true signification

2. Uji Homogenitas
Uji homogenitas dimaksudkan untuk menguji setiap kelompok yang akan dibandingkan memiliki variasi yang sama. Berdasarkan data tabel 2 . dapat diketahui bahwa nilai signifikasi uji homogenitas antara kelas eksperimen dengan kelas kontrol di SD Negeri Siwungkuk adalah 0,403>0,05. Hal ini berarti varian dari dua atau lebih kelompok populasi data sama atau homogen.

Tabel 2. Tabel Uji Homogenitas

\begin{tabular}{llcc}
\hline $\begin{array}{l}\text { Levene } \\
\text { Statistic }\end{array}$ & df1 & df2 & Sig. \\
\hline .711 & 1 & .50 & .403 \\
\hline
\end{tabular}

3. Ujit

Uji kesamaan rata-rata digunakan untuk mengetahui perbedaan antara dua variabel setelah diberi perlakuan. Berdasarkan hasil penelitian dapat diketahui bahwa nilai sig $=0,000<0,05$. $\mathrm{Hal}$ ini berarti $\mathrm{H}_{0}$ ditolak artinya bahwa ada perbedaan antara kelompok eksperimen dengan kelompok kontrol. Oleh karena itu, dikatakan bahwa media pembelajaran puzzle dapat berpengaruh terhadap hasil belajar kognitif di SD Negeri Siwungkuk. Jadi, media tersebut dapat diterima.

Penggunaan media puzzle dalam proses pembelajaran bergantung pada kreasi dan inisiatif dari pengajar. Kreativitas dapat berkembang dengan baik menuju titik optimal jika ditunjang dua faktor utama yaitu lingkungan, sarana dan prasarana. Lingkungan yang baik dalam proses pengembangan kreativitas dapat mengantarkan pribadi manusia kreatif. Melalui bermain anak memperoleh pelajaran yang mengandung aspek perkembangan kognitif, sosial, emosi dan fisik. Begitu juga dengan seorang guru. Guru harus mampu menumbuhkkan kreativitasnya. Salah satu contoh yaitu guru bisa memanfaatkan sesuatu yang berada di 
lingkungan sebagai media pembelajaran yang kreatif. Sama halnya bahwa media pembelajaran harus menuntut kreativitas gurunya agar proses pembelajaran bisa menyenangkan[2]. Misalnya dengan media pembelajaran education games. Melalui kegiatan bermain dengan berbagai macam bentuk permainan, anak dirangsang untuk berkembang menuju totalitas kepribadian.

Hasil belajar kognitif pada peserta didik dapat dikatakan meningkat dengan adanya puzzle. Hal ini sejalan dengan penelitian [10] bahwa media peta puzzle terbukti lebih efektif diterapkan dalam materi peta dibanding dengan media peta konvensional. Media peta puzzle terbukti lebih efektif diterapkan dalam materi peta dibanding dengan media peta konvensional Pengetahuan belajar peta dapat ditunjukan dalam pembelajaran. Hal ini menunjukkan bahwa media pembelajaran puzzle merupakan proses belajar peserta didik yang membutuhkan tahap melakukan, mengungkapkan, menganalisis, menyimpulkan dan menerapkan materi peta dalam kegiatan pembelajaran.

Peneliti [5] mengungkapkan bahwa penggunaan media puzzle dapat membantu untuk menstimulus perkembangan kognitif anak, terutama pada perkembangan pemecahan masalah anak usia 5-6 tahun.

Tujuan pembelajaran pada materi peta bisa terpenuhi dilihat dari segi hasil kognitif peserta didik. Oleh karena itu, ada kesinambungan antara materi peta dengan media pembelajaran. Keduanya harus berjalan secara bersamaan secara maksimal. Agar peserta didik dapat mencapai ketuntasan pada materi peta, guru harus mengintegrasikan dengan media pembelajaran yang menarik, inovatif, dan kreatif.

\section{SIMPULAN}

Media pembelajaran adalah segala sesuatu yang dapat menyalurkan pesan, dapat merangsang fikiran, perasaan, dan kemauan peserta didik sehingga dapat mendorong terciptanya proses belajar pada diri peserta didik. Penelitian menunjukkan bahwa ada pengaruh media puzzle terhadap hasil belajar kognitif peserta didik di Sekolah Dasar. Hasil belajar peserta didik dapat diketahui bahwa nilai sig $=0,000<0,05$. Hal ini menunjukkan bahwa ada perbedaan antara kelompok eksperimen dengan kelompok kontrol. Oleh karena itu, dapat dikatakan bahwa media pembelajaran puzzle ini dapat meningkatkan kemampuan peserta didik terhadap hasil belajar kognitif di SD Negeri Siwungkuk.

\section{Daftar Pustaka}

[1] Kurniawan, Prasetyo Yuli, 2019, Keefektifan Penggunaan Bahan Ajar Interaktif yang Berbasis Kearifan Lokal Brebes dalam Mata Kuliah Semantik, Jurnal Pendidikan Bahasa dan Sastra Indonesia, Vol. 3 No. 2 Hal 170176. Retrieved from https://jurnal.uisu.ac.id/index.ph $\mathrm{p} /$ Bahastra/article/download/115 9/923.

[2] Sujarno, D. \& Sukirno, 2015, Pengembangnan Media Pembelajaran IPS dengan Tema Pemanfaatan dan Pelestarian Sungai untuk Peserta didik Kelas VII SMP, Harmoni Sosial: Jurnal Pendidikan IPS, Vol. 2 No. 2 Hal 115-125, Retrieved from https://journal.uny.ac.id/index.p hp/hsjpi/article/view/7663.

[3] Rumakhit, Nur, 2017, Pengembangan Media Puzzle untuk Pembelajaran Materi 
Jurnal KONTEKSTUAL, Volume 1, No. 1, Agustus 2019, pp. 1-6

Mengidentifikasi Beberapa Jenis Simbiosis dan Rantai Makanan Kelas IV Sekolah Dasar Tahun 2016/ 2017, Jurnal SimkiPedagogia, Vol. 01 N0. 02 Tahun 2017, Retrieved from http://simki.unpkediri.ac.id/mah asiswa/file_artikel/2017/55730c 32a47f7fdf96d67740f223c0b2.p df.

[4] Sanaky, Hujair AH, 2013, Media Pembelajaran Interaktif-Inovatif. Bantul: Kaukaba Dipantara.

[5] Sari, Yesi Ratna, 2018, Pengaruh Penggunaan Puzzle Terhadap Peningkatan Perkembangan Kognitif Anak Usia 5-6 Tahun di TK LPM Raman Endra, Skripsi. Bandar Lampung: Universitas Lampung.

[6] Aziz, Farhan, Aktualisasi TTB (Teori Taksonomi Bloom) melalui Drama Kepahlawanan Guna Penanaman Pendidikan Karakter pada Peserta Didik, Jurnal Bahasa dan Sastra Indonesia dalam Konteks Global.Hal. 715724. Retrieved from https://journal.uny.ac.id/index.php /mip/article/download/7132/6155.
[7] Khomsoh, Rosiana, Penggunaan Media Puzzle untuk meningkatkan hasil belajar siswa dalam pembelajaran Ilmu Pengetahuan Sosial di Sekolah Dasar, Jurnal PGSD UNESA, Hal. 1-11, Retrieved from https://media.neliti.com/media/pu blications/250946-penggunaanmedia-puzzle-untuk-meningkatk252f878f.pdf.

[8] Pramono, Suwito Eko, 2013, Hakikat Pendidikan Ilmu Pengetahuan Sosial. Semarang: Widya Karya.

[9] Sugiyono, 2010, Metode Penelitian Kuantitatif, Kualitatif dan $R \& D$. Bandung: Alfabeta.

[10] Saifullah, Pargito, \& Darsono, 2013, Pengembangan Media Peta Puzzle dalam Pembelajaran IPS Madrasah Ibtidaiyah Uswatun Hasanah Merambung. Jurnal Studi Sosial Vol. 1 No. 3 Hal 110. Retrieved from http://jurnal.fkip.unila.ac.id/index. php/JSS/article/view/1712. 